\title{
Efektivitas Perawatan Dasar Bayi Terhadap Pengetahuan dan Keterampilan Ibu Merawat Bayi BBLR
}

\author{
Helatul Mardiah', Zainal Munir ${ }^{2}$, Kholisotin ${ }^{3}$, Ahmad Kholid Fauzi', Abdul Hamid Wahid5 \\ 1. F.Kes, Universitas Nurul Jadid, email: helatul.mardiah@gmail.com \\ 2. F.Kes, Universitas Nurul Jadid, email: zainalmunirnj@gmail.com \\ 3. F.Kes, Universitas Nurul Jadid, email: nerslilis18@yahoo.co.id \\ 4. F.Kes, Universitas Nurul Jadid, email: Kholid0404@gmail.com \\ 5. F.Kes, Universitas Nurul Jadid, email: hamidw@gmail.com
}

\begin{abstract}
Abstrak
Bayi Berat Badan Lahir Rendah (BBLR) rendah merupakan berat badan bayi yang lahir kurang dari 2500 gram tanpa memandang masa gestasi atau usia kehamilan. Tujuan penelitian ini adalah untuk mengetahui tingkat pengetahuan ibu merawat bayi BBLR sebelum dan sesudah diberikan perawatan dasar BBLR. mengetahui tingkat keterampilan ibu dalam memberikan perawatan terhadap bayi BBLR sebelum dan sesudah diberikan perawatan dasar bayi BBLR. Metode penelitian ini menggunakan total sampling dengan rancangan one-group pra-post test design dengan tujuan mengidentifikasi tingkat pengetahuan dan keterampilan ibu dalam merawat bayi BBLR. populasi penelitian ini adalah ibu yang memiliki bayi BBLR yang pernah melahirkan dan dirawat di RSUD dr.H. Koesnadi Bondowoso dengan total sampel 42 responden. Uji variabel menggunakan uji paired $\mathrm{T}$ test. Hasil penelitian dengan uji paired $\mathrm{T}$ test $(\alpha=0.05)$ sebanyak 42 responden menunjukkan bahwa tingkat pengetahuan dan tingkat keterampilan ibu terhadap perawatan bayi BBLR memiliki nilai signifikan 0.000, P.Value kedua kelompok penelitian ini adalah $\rho=0.000$, pada tingkat pengetahuan dan keterampilan $(\alpha=<0.05)$. Ada peningkatan yang signifikan dari tingkat pengetahuan dan tingkat keterampilan ibu setelah diberikan edukasi perawatan dasar bayi BBLR.
\end{abstract}

Kata kunci : Perawatan Dasar Bayi BBLR, Pengetahuan, keterampilan.

\section{The Effectiveness Of Babies Basic Care Towards Knowledge and Maternal Skills Of LBW Babies}

\begin{abstract}
Low Birth Weight ( $L B W$ ) is the weight of baby born less 2500 grams regardless of gestation or gestational age. The purpose of this research is to know the level of knowledge of mothers caring for LBW babies before and after giving basic care of $L B W$ babies. Knowing the level of maternal skills in providing care for $L B W$ before and after giving basic care. This research method use sampling total with one-group pre-post test design with the aim of identifying the level of knowledge and mothers skills in caring for LBW babies. The study population was the mother who had LBW babies who had given birth and treated at the RSUD Dr. H. Koesnadi Bondowoso with a total sample 42 respondents. This variable test using paired T test. The result of this research with a paired T test ( $\alpha=0.05) 42$ respondents indicated that the level of knowledge and the level of maternal skills towards LBW babies care had a significant value 0.000, P. Value of these two research groups was $\rho=0.000$, at the level of knowledge and skills $(\alpha=<0.05)$. There is a significant increase from the level of knowledge and the level of maternal skills after giving the basic caring education for LBW babies.
\end{abstract}

Key words: the basic care of LBW babies, knowledge, Abilty

\section{Pendahuluan}

Berat badan lahir rendah (BBLR) merupakan berat badan kurang dari 2500 gram saat lahir tanpa memandang kehamilan usia .(Sharma et al., 2015).
Diketahui bahwa pada tahun 2011, 15\% bayi di seluruh dunia lebih dari 20 juta jiwa terjadi kejadian BBLR, lahir dengan BBLR.(Sharma et al., 2015). Diketahui bahwa pada tahun 2011, 15\% bayi di 
seluruh dunia lebih dari 20 juta jiwa terjadi kejadian BBLR, lahir dengan BBLR. (UNICEF, 2018) Angka kejadian di Indonesia sangat bervariasi antara satu daerah dengan daerah lain. Berdasarkan laporan menunjukkan bahwa persentase BBLR di indonesia sebesar 10,2\%. Menurut pendidikan dan kuintil indeks kepemilikan terlihat adanya kecenderungan semakin tinggi pendidikan dan kuintil indeks kepemilikan, semakin rendah prevalensi BBLR. Menurut jenis pekerjaan, persentase BBLR tertinggi pada anak balita dengan kepala rumah tangga yang tidak bekerja $11,6 \%$, sedangkan persentase terendah pada kelompok pekerjaan pegawai $8,3 \%$. Persentase BBLR di perdesaan 11,2\% lebih tinggi daripada di perkotaan 9,4\%.(Kemenkes RI, 2013).

Menurut laporan, angka kejadian BBLR Di Propinsi Jawa Timur persentase BBLR meningkat dari 2,79\% pada tahun 2010 menjadi $3,32 \%$ pada tahun 2013.(Sholiha \& Sumarmi, 2014). Sedangkan meurut laporan terbaru, Tercatat pada tahun 2016 sebesar $3,6 \%$. Kabupaten situbondo merupakan kabupaten dengan kejadian BBLR tertinggi seprovinsi jawa timur dengan persentase 7,8\%, kabupaten madiun memiliki posisi kedua dengan persentase $7,7 \%$, dan kabupaten bondowoso merupakan kabupaten dengan kkejadian BBLR tertinggi ketiga sejawa timur dengan persentase 6,9\%. (Dinkes Prov. Jatim, 2016). Tercatat bahwa persentase BBLR bondowoso menunjukkan pada tahun 2012 tercatat $4,6 \%$, tahun 2013 tercatat $5,41 \%$, tahun 2014 tercatat $5,6 \%$, tahun 2015 tercatat $6,2 \%$ dan data terbaru pada tahun 2016 tercatat $6,9 \%$ atau 706 bayi dengan komposisi laki - laki sebanyak 361 bayi, dan perempuan sebanyak 345 bayi dari jumlah bayi lahir hidup sebanyak 10.337 bayi. Jika lebih dispesifikkan lagi, kecamatan dengan BBLR tetinggi di kabupaten bondowoso yaitu di kecamatan sukosari dengan persentase 15,9 \%. (Dinkes Kab. Bondowoso, 2016).

Pemerintah kabupaten bondowoso mengupayakan pembangunan kesehatan untuk menurunkan angka kematian pada neonatus dengan memelihara dan meningkatkan pelayanan kesehatan yang bermutu, merata dan terjangkau serta mendorong kemandirian masyarakat untuk hidup serta berprilaku sehat sesuai dengan program atau kegiatan kesehatan yang ada. Namun berdasarkan data, tampak bahwa laju kejadian BBLR terus mengalami peningkatan dalam lima tahun terakhir yaitu pada tahun 2012-2016.

BBLR terjadi karena beberapa faktor, yaitu faktor ibu seperti usia ibu yang $<20$ tahun atau usia yang $>35$ tahun. Faktor penyakit ibu sperti toksemia gravidarum, pendarahan antepartum, trauma fisik. faktor keadaan sosial seperti golongan sosial ekonomi rendah, faktor janin seperti hidromniaon, gemeli, dan faktor lingkungan seperti radiasi zat racun. (Tando, 2016)

Diketahui bahwa ada hubungan yang signifikan antara usia kehamilan, paritas, kadar HB, preeklampsi, eklampsi, kehamilan ganda dan pendidikan ibu terhadap kejadian BBLR. Tidak ada hubungan signifikan antara usia ibu, diabetes mellitus, jenis kelamin bayi dan pekerjaan ibu dengan kejadian BBLR. Variabel yang paling dominan mempengaruhi kejadian BBLR adalah usia kehamilan. (Kumalasari, 2018) Sebuah penelitian di negara ethiopia, yang merupakan penyumbang terbesar terhadap beban global kematian bayi baru lahir. Namun mampu memenuhi sasaran global dan nasional dengan mengurangi angka kematian neonatal / NMR (neonatal mortality rate), Hal ini terjadi karena negara ethiopia berkomitmen untuk meningkatkan kualitas perawatan ibu dan bayi baru lahir. (Yigzaw et al., 2017) Penelitian yang dilakukan di kota Sumenep juga menemukan bahwa pendidikan ibu rendah 4,4 kali berisiko melahirkan BBLR. (Festi pw, 2011)

Penatalaksanaan bayi BBLR perlu di dukung dengan pengetahuan yang baik, dari pengetahuan ini akan menunjang terhadap pemberian penatalaksanaan yang berkualitas dan aman terhadap bayi BBLR. Dalam hal ini, penatalaksanaan perawatan 
pada bayi yang dilakukan oleh seorang ibu meliputi mempertahankan suhu dan kehangatan bayi BBLR di rumah, memberikan ASI kepada bayi BBLR di rumah dan mencegah terjadinya infeksi bayi BBLR.

Perawatan dasar bayi perlu dilakukan terhadap ibu yang memiliki bayi dengan berat badan lahir rendah (BBLR) yang bertujuan untuk mencegah kematian pada neonatus dengan meningkatkan pengetahuan ibu serta terampil dalam perawatan dasar bayi BBLR. Pada penelitian ini, peneliti menganalisa tentang kefektifan perawatan dasar bayi dengan memberikan pelatihan untuk pengetahuan orang tua yang merawat bayi BBLR. Pelatihan perawatan dasar bayi diharapkan untuk membantu ibu lebih siap, mandiri, serta terampil dalam merawat bayi BBLR.

\section{Metode}

1. Desain, tempat, dan waktu

Jenis penelitian ini adalah PraEksperimental dengan menggunakan rancangan pra-pascates dalam satu kelompok (one-group pra-post test design) untk melihat tingkat pengetahuan dan keterampilan ibu merawat bayi BBLR. Penelitian dilakukan 1 bulan.yaitu pada tanggal 23, Januari sampai 24 Februari 2019. Penelitian ini di RSUD dr.H.Koesnadi Bondowoso

2. Jumlah dan Cara Pengumpulan data

Populasi pada penelitian ini seluruh ibu yang memiliki bayi BBLR yang di pernah dirawat inap ataupun ibu yang melahirkan di RSU dr.H.Koesnadi Kabupaten Bondowoso. Teknik pengambilan sampel penelitian ini dengan cara total sampling yaitu sebanyak 42 responden. Apabila responden tidak menyetujui untuk diberikan pelatihan perawatan dasar bayi BBLR, maka responden tidak dimasukkan sebagai subjek penelitian. Metode pengumpulan data menggunakan kuisioner untuk mengetahui tingkat pengetahuan dan observasi untuk mengetahuai tingkat keterampilan ibu dalam merawat bayi dengan BBLR.
3. Jumlah dan Cara Pengumpulan data

Pengumpulan data responden yaitu dengan lembar kuosioner. Berdasarkan hasil wawancara, responden penelitiaan ini adalah seluruh ibu bayi BBLR yang pernah di rawat inap ataupun ibu yang melahirkan di RSU dr.H.Koesnadi Bondowoso dari bulan November 2018, Desember 2018 sampai tanggal 03 Januari 2019 sebanyak 42 bayi BBLR. Data BBLR diperoleh dari buku kelahiran di ruang seruni RSU dr.H.Koesnadi Bondowoso. Karakteristik responden penelitian ini meliputi umur ibu dan tingkat pendidikan ibu. Variabel pengetahuan dan keterampilan dengan menggunakan nilai (score). Untuk jawaban pada kuesioner pengetahuan nilai (score) benar $=1$, salah $=0$, Pada lembar observasi keterampilan atau praktik nilai (score) tidak terampil $=0$, terampil $=1$. Sedangkan isian data umum responden, menggunakan kode, yaitu untuk umur $<20 \mathrm{Th}=1,20-30 \mathrm{Th}$ $=2$ dan umur $>30 \mathrm{Th}=3$. Sedangkan untuk kode tingkat pendidikan, tidak berpendidikan $=0, \mathrm{SD}=1, \operatorname{SLTP}=2$, SLTA $=3$.

4. Pengolahan dan analisis data

Analisa data dilakukan untuk menjawab tujuan penelitia, melakukan pengujian hipotesis, serta analisa data yaitu secara univariat dan bivariat. Analisa univariat ini dilakukan untuk menjelaskan atau mendeskripsikan karakteristik masing - masing variabel yang diteliti yaitu umur ibu dan tingkat pendidikan ibu. Sedangkat analisis bivariat dilakukan untuk melihat tingkat pengetahuan dan keterampilan ibu merawat bayi BBLR pretest dan posttest. peneliti menggunakan Uji paired t-test dengan aplikasi IBM SPSS Statistics 24

\section{Hasil Penelitian}

1. Umur Ibu Bayi BBLR 
Tabel 1. Karakteristik ibu bayi BBLR di RSUD dr.H.Koesnadi Bondowoso $\mathrm{N}=42$

\begin{tabular}{|c|c|c|c|}
\hline \multirow{2}{*}{ No } & \multirow{2}{*}{ Karakteristik } & \multicolumn{2}{|c|}{$\mathrm{n}=42$} \\
\hline & & Frekuensi & $(\%)$ \\
\hline \multirow[t]{4}{*}{1} & Tingkat pendidikan & & \\
\hline & $<20$ tahun & 4 & 9.5 \\
\hline & 20-30 tahun & 31 & 73.8 \\
\hline & $>30$ tahun & 7 & 16.7 \\
\hline \multicolumn{2}{|c|}{ Total } & 42 & 100.0 \\
\hline \multirow[t]{4}{*}{2} & Umur & & \\
\hline & Tidak berpendidikan & 3 & 7.1 \\
\hline & SD & 28 & 66.7 \\
\hline & SMP & 11 & 26.2 \\
\hline Tota & & 42 & 100.0 \\
\hline
\end{tabular}

2. Analisa Bivariat

Tabel 2. Hasil T-Test tingkat pengetahuan dan keterampilan ibu terkait perawatan bayi BBLR di RSUD dr.H.Koesnadi Bondowoso

\begin{tabular}{|c|c|c|c|c|c|c|}
\hline & \multicolumn{6}{|c|}{ Paired Deffrences } \\
\hline & Mean & $\begin{array}{c}\text { Std. } \\
\text { Deviation }\end{array}$ & $\begin{array}{l}\text { Std. } \\
\text { Error }\end{array}$ & $\mathrm{t}$ & df & $\begin{array}{l}\text { Sig (2- } \\
\text { Tailed }\end{array}$ \\
\hline \multicolumn{7}{|c|}{ Tingkat pengetahuan } \\
\hline $\begin{array}{l}\text { Pre- } \\
\text { post }\end{array}$ & -.14262 & .04037 & .0062 & -22.896 & 41 & .000 \\
\hline \multicolumn{7}{|c|}{ Tingkat keterampilan } \\
\hline $\begin{array}{l}\text { Pre- } \\
\text { post }\end{array}$ & -.22000 & .13556 & .02092 & -10.518 & 41 & .000 \\
\hline
\end{tabular}

\section{Pembahasan}

1. Umur Ibu

Karakteristik ibu bayi BBLR dalam penelitian ini Berdasarkan tabel 1. dapat diketahui bahwa usia $<20$ tahun sebanyak 4 orang $(9,5 \%), 20-30$ tahun sebanyak 31 orang $(73,8 \%)$ dan $>30$ tahun sebanyak 7 orang $(16,7 \%)$. Hasil penelitian ini menunjukkan bahwa mayoritas umur ibu bayi BBLR berumur 20-30 tahun yaitu 31 orang $(73,8 \%)$ artinya, bahwa ibu yang berusia 20-30 tahun cenderung mengalami kejadian BBLR.

Hasil penelitian ini tidak sesuai dengan teori Manuaba (2010) yang menyatakan faktor penyebab terjadinya ibu melahirkan bayi BBLR yang salah satunya disebabkan karena usia ibu kurang dari 20 tahun atau lebih dari 35 tahun. Yang berarti bahwa usia reproduksi sehat adalah pada usia 20-35 tahun. Dimana pada masa ini merupakan waktu yang optimal bagi psikologis ibu serta organ reproduksi wanita pada masa ini sudah siap untuk matang, sehingga pertumbuhan dan perkembagan bayi di dalam rahim ibu bisa tumbuh secara optimal dan lahir secara normal. (Manuaba, 2010)

Namun hal ini di perkuat oleh penelitian yang dilakukan oleh Feibi, dkk pada tahun 2015 yang menunjukkan hasil dari 70 responden yang berada pada umur $>20$ tahun sebanyak 22 responden dengan kategori bayi dengan BBLR sebanyak $(31,4 \%)$, dan bukan BBLR sebanyak $(2,9 \%)$ dan umur tidak beresiko dengan kategori BBLR sebanyak (21,4\%), dan bukan BBLR sebanyak (20,0\%). (rantung, feibi, 2015)

2. Tingkat Pendidikan ibu

Karakteristik ibu bayi BBLR dalam penelitian ini berdasarkan tabel 1. Dapat diketahui bahwa ibu tidak berpendidikan sebanyak $3(7,1 \%)$, ibu berpendidikan tamatan SD sebanyak $28 \quad(66,7 \%)$, sedangkan ibu yang pendidikannya tamat SMP sebanyak 11 (26,2\%). Hasil penelitian ini menunjukkan bahwa mayoritas tingkat pendidikan responden tamatan SD yaitu sebanyak $28(66,7 \%)$.

Hal ini sesuai dengan hasil penelitian Nuryani (2015) menunjukkan bahwa ibu bayi yang melahirkan BBLR dengan pendidikan ibu yang rendah sebanyak $45,5 \%$. Sedangkan kategori ibu yang berpendidikan tinggi melahirkan bayi tidak BBLR sebanyak $89,8 \%$ dengan Nilai $p=0,017$ yang artinya bahwa terdapat hubungan yang signifikan antara tingkat pendidikan dengan kejadian BBLR. (Nuryani dkk, 2015).

Hal ini sesuai dengan hasil penelitian Demelash et al. (2015) yang menunjukkan bahwa pendidikan formal yang rendah berisiko enam kali melahirkan BBLR. (demelash, 2015)

3. Analisis Tingkat Pengetahuan Ibu Merawat Bayi BBLR Sebelum dan Sesudah Diberikan Edukasi 
Berdasarkan tabel 2. didapatkan data peningkatan pengetahuan responden sebelum dan sesudah diberikan edukasi. Hal tersebut dapat dilihat dari nilai mean -14262 dan nilai standart deviasi sebesar 04037 dengan nilai segnifikan (P-Value) sebesar 0.000 yang berarti $\rho<0.05$ sehingga $H_{0}$ ditolak dan $H_{a}$ diterima yang artinya adanya pengaruh evektifitas perawatan bayi dengan BBLR dengan tingkat pengetahuan yang dimiliki oleh masing-masing responden.

Hal ini diperkuat oleh penelitian yang dilakukan oleh dewi siti (2010) bahwa pengaruh perawatan metode kangooro (PMK) terhadap pertumbuhan bayi dan tingkat pengetahuan ibu didapatkan hasil bahwa dari 16 responden yang mendapatkan PMK selama 1 minggu, terdapat pengaruh yang signifikan antara berat badan sebelum dan sesudah dilakukan PMK dengan $p$ value 0.000 , dengan perbedaan rata-rata berat badan sebelum dan sesudah dilakukan PMK sebesar 259,38 gram setiap minggu

4. Analisis Tingkat keterampilan Ibu Merawat Bayi BBLR Sebelum Dan Sesudah Diberikan Edukasi

Berdasarkan tabel 2. didapatkan data peningkatan keterampilan responden sebelum dan sesudah diberikan edukasi. Hal tersebut dapat dilihat dari nilai mean -22000 dan nilai standart deviasi sebesar 13556 dengan nilai segnifikan (P-Value) sebesar 0.000 yang berarti $\rho<0.05$ sehingga $\mathrm{H}_{0}$ ditolak dan $\mathrm{H}_{\mathrm{a}}$ diterima yang artinya adanya pengaruh evektifitas perawatan bayi dengan BBLR dengan tingkat keterampilan yang dimiliki oleh masing-masing responden.

Peneliti berasumsi bahwasanya salah satu tingkat keberhasilan dalam perawatan BBLR salah satunya adalah faktor keterampilan ibu, karena ibu tidak semua ibu dapat melakukan perawatan dasar pada bayi sekalipun ibu memiliki pengetahuan yang cukup terkait perawatan dasar bayi BBLR. Peneliti juga berasumsi bahwa dalam praktik keterampilan ibu harus didasari dengan pengetahuan, dengan tujuan agar pengetahuan yang diberikan mampu diterapkan dan ibu lebih percaya diri dalam melakukan perawatan pada bayi.

5. Analisis Tingkat keterampilan Ibu Merawat Bayi BBLR Sebelum Dan Sesudah Diberikan Edukasi

Berdasarkan hasil uji SPSS dengan menggunakan metode T-Test mendapatkan hasil bahwa antara tingkat pengetahuan dan tingkat keterampilan ibu terhadap perawatan bayi dengan BBLR memiliki nilai signifikan 0.000, P.Value kedua kelompok penelitian menunjukkan bahwa nilai probabilitas pada penelitian ini adalah $\rho=0.000$ pada tingkat pengetahuan dan keterampilan $(\alpha=<0.05)$ sehingga $H_{a}$ diterima dan $H_{0}$ ditolak, yang artinya adanya pengaruh atau hubungan antara variabel perawatan dasar bayi BBLR dengan variabel pengetahuan dan keterampilan.

Peneliti Demelash et al. (2015) menyatakan dalam penelitiannnya bahwa pendidikan formal yang rendah berisiko enam kali melahirkan BBLR. Menurut peneliti keadaan awal (sebelum diberikan edukasi) penelitian ini didapatkan tingkat pengetahuan dan keterampilan ibu dalam perawatan bayi BBLR yang kurang baik.

Peneliti melakukan observasi sebelum dan sesudah diberikan edukasi didapatkan ada peningkatan yang signifikan tingkat pengetahuan ibu terhadap perawatan dasar bayi BBLR. diketahui bahwa mayoritas pendidikan responden dengan tingkat pendidikan sekolah dasar (SD) yaitu sebanyak 28 orang $(66,7 \%)$ namun ibu bayi mampu melakukan perawatan dasar bayi BBLR sesuai dengan prosedur yang aman dengan tingkat pendidikan yang rendah, Hal ini terjadi karena selain diberikan edukasi, ibu bayi juga dibekali modul praktis dan simpel untuk dibawa kemanapun. modul tersebut dirancang semenarik mungkin agar mudah dibaca oleh ibu bayi BBLR. dengan tujuan apabila ada yang lupa dengan salah satu 
materi yang telah dijelaskan, ibu bisa mengingat dengan membuka modul kembali sesuai dengan prosedur yang telah dijelaskan. Ternyata Modul ini sangat efektif untuk ibu dalam melakukan perawatan pada bayi BBLR dengan prosedur yang aman.

Peneliti berasumsi bahwasanya salah satu tingkat keberhasilan dalam perawatan bayi BBLR, selain dari faktor pengetahuan ibu, ibu harus terampil dalam melakukan perawatan dasar bayi BBLR. karena tidak semua ibu dapat melakukan perawatan dasar pada bayi sekalipun ibu memiliki pengetahuan yang cukup terkait perawatan dasar bayi BBLR. Peneliti juga berasumsi bahwa dalam praktik keterampilan ibu harus didasari dengan pengetahuan, dengan tujuan agar pengetahuan yang diberikan mampu diterapkan dan ibu lebih percaya diri dalam melakukan perawatan pada bayi. Setelah diberikan edukasi dan modul terhadap responden hasil menunjukan bahwasanya ada peningktan yang signifikan pada tingkat pengetahuan dan keterampilan terhadap perawatan bayi dengan BBLR di RSU.dr.H.Koesnadi Bondowoso.

\section{Simpulan}

Simpulan dari penelitian ini adalah Mayoritas ibu yang berumur 20-35 tahun (usia tidak beresiko kejadian BBLR) melahirkan bayi BBLR di RSUD dr.H.Koesnadi Bondowoso, Adanya peningkatan yang signifikan pada tingkat pengetahuan dan keterampilan ibu bayi BBLR. P.Value keduanya menunjukkan nilai probabilitas $(\rho=0.000)$ pada tingkat pengetahuan dan keterampilan $(\alpha=<0.05)$, Adanya keefektifan modul terhadap ibu bayi BBLR dalam penerapan perawatan dasar bayi BBLR setelah di intervensi edukasi pada ibu bayi BBLR.

\section{Daftar Pustaka}

Demelash, Et Al. (2015). Risk Factors For
Low Birth Weight In Bale Zone Hospitals, South-East Ethiopia. Bmc Pregnancy And Childbirth, 15.No 264-.

Dinkes Kab. Bondowoso. (2016). Profil Kesehatan Kabupaten Bondowoso Tahun 2016. Www.Dinkesbondowoso.Id.

Diakses 27 September 2018 Pukul 20.00 .

Dinkes Prov. Jatim. (2016). Profil Kesehatan Profinsi Jawa Timur Tahun 2016. Www.Depkes.Go.Id. Diakses 27 September 2018 Pukul 20.00.

Festi Pw. (2011). Analisis Faktor Risiko Pada Kejadian Berat Badan Lahir Rendah Di Kabupaten Sumenep.

Kemenkes Ri. (2013). Riset Kesehatan Dasar. Jakarta: Balitbang Kemenkes Ri.

Kumalasari, I. (2018). Faktor Resiko Dan Angka Kejadian Berat Badan Lahir Rendah (BBLR) Dirsup Dr.Mohammad Hosin Palembang Tahun 2014, 9(1365), 41-52.

Manuaba. (2010). Ilmu Kebidanan Penyakit Kandungan Dan Kb. Jakarta: Egc.

Nuryani Dkk. (2015). Kejadian Berat Badan Lahir Rendah Di Tinelo Kabupaten Gorontalo Dan Faktor Yang Mempengaruhinya, 12 No 01.

Rantung, Feibi, Almeira. (2015). Hubungan Usia Ibu Bersalin Dengan Kejadian Bayi Berat Badan Lahir Rendah Dirumah Sakit Pancaran Kasih Gmim Manado. Ejurnal Keperawatan, 03, No.3.

Sharma, S. R., Giri, S., Timalsina, U., Bhandari, S. S., Basyal, B., Wagle, K., \& Shrestha, L. (2015). Low Birth Weight At Term And Its Determinants In A Tertiary Hospital of Nepal:A CaseControl Study. Plos One, 10(4), 1-11. Https://Doi.Org/10.1371/Journal.Pone.0 123962

Sholiha, H., \& Sumarmi, S. (2014). Analisis Risiko Kejadian Berat Bayi Lahir Rendah ( BBLR) Pada Primigravida, 2007.

Tando, N. M. (2016). Asuhan Kebidanan Neonatus, Bayi, Dan Anak Balita. Jakarta: Egc.

Unicef. (2018). . Undernutrition Contributes 
To Nearly Half Of All Death In Children Under 5 And Is Widespread In Asia And Africa.

Yigzaw, T., Abebe, F., Belay, L., Assaye, Y., Misganaw, E., Kidane, A., ... Kim, Y. M. (2017). Quality Of Midwife-Provided
Intrapartum Care In Amhara Regional State, Ethiopia. Bmc Pregnancy And Childbirth, 17(1), $1-13$. Https://Doi.Org/10.1186/S12884-017$1441-2$ 